\section{$\underset{\substack{\text { hommes } \\ \text { \& migrations }}}{ }$}

\section{Hommes \& migrations}

Revue française de référence sur les dynamiques

migratoires

\section{$1322 \mid 2018$}

Exposer les migrations

\title{
Kkrist Mirror, Manouches
}

Paris, Steinkis 2016, 160 p., $20 €$.

\section{Mustapha Harzoune}

\section{(2) OpenEdition \\ 1 Journals}

\section{Édition électronique}

URL : https://journals.openedition.org/hommesmigrations/6782

DOI : 10.4000/hommesmigrations.6782

ISSN : 2262-3353

Éditeur

Musée national de l'histoire de l'immigration

\section{Édition imprimée}

Date de publication : 1 juillet 2018

Pagination : 168-169

ISBN : 978-2-919040-42-1

ISSN : 1142-852X

\section{Référence électronique}

Mustapha Harzoune, «Kkrist Mirror, Manouches », Hommes \& migrations [En ligne], 1322 | 2018, mis en ligne le 01 juillet 2018, consulté le 21 janvier 2022. URL : http://journals.openedition.org/

hommesmigrations/6782; DOI : https://doi.org/10.4000/hommesmigrations.6782 


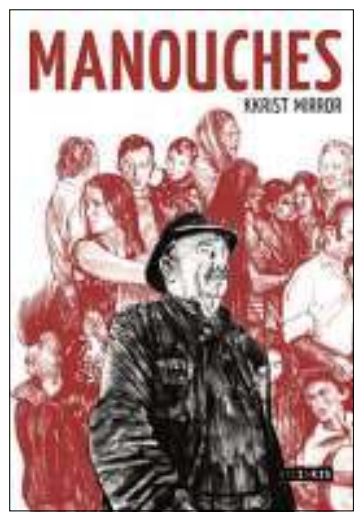

\section{Kkrist Mirror}

Manouches

D’après un récit raconté par Daniel Boitard, instituteur des Gens du voyage, postface d'Henriette Asséo, Steinkis, 2016, 160 pages, 20 euros.

Kkrist Mirror plonge le lecteur dans le quotidien d'une famille manouche, celle d'Archange, dit Tenoir, et de Marie, surnommée Blanche. Du patchivalo (patriarche) et de son épouse sont nés rien moins que sept enfants, vingt-cinq petits-enfants et sept arrières petitsenfants. On ne chôme pas! II faut dire que les marmots ici sont roi, qu'on ne plaisante pas avec la famille et que la solidarité n'est pas un vain mot. Au milieu de cette smala, évolue un gadjo, Daniel, l'instituteur itinérant, confident et ami de Tenoir qui prodigue conseils et enseignement -y compris sur l'histoire, l'internement, dans des camps bien français, et l'extermination des Tsiganes.

L'album montre ce qu'endurent ces Français "entièrement à part » : injustices, persécutions, hostilités, racismes..., tout et tous leur tombent sur le paletot, depuis les services administratifs, judiciaires, la gendarmerie et même le vulgum pecus à l'entendement embrumé de poncifs surannés et d'ignorance - mère de cette méchanceté qui ne voit que louches Mercedes tractant d'immenses caravanes. Tout un chacun ignore (et refuserait illico) leurs conditions de vie : ces campings qui, en hiver, n'offrent le choix qu'entre le froid et l'asphyxie en se chauffant avec du bois recouvert de peinture toxique. L'obligation de se terrer dans des usines désaffectées et insalubres où menacent maladies et dangers : comme voir un fils se noyer dans de l'eau croupie. Sait-on que Mercedes et caravanes, objets de tous les fantasmes, se trimballent dans "un paysage d'exclusion", pour finir dans "des camps sans barbelé" ". Les plus cons, c'est ceux qui nous envient, aveugles de not'misère. " Kkrist Mirror raconte ce quotidien de reclus, de réprouvés confrontés ici à un huissier, aux tribunaux, au racisme d'un bistrotier et, le plus souvent et le plus craint, à l'indifférence ou à la brutalité d'un klisté (un flic). Dans les cauchemars de Tenoir, la peur du klisté se mêle aux camps et au samudaripen, le génocide tsigane.

Rien d'original sous la plume des artistes et créateurs : répéter et encore répéter pour peut-être gagner sur la nuit. Kkrist Mirror le fait avec conviction et militantisme, sans manquer à ses devoirs d'artiste et à sa sensibilité de créateur. L'esthétique reste au service de l'émotion. Il y a les dessins, à l'encre de chine, le trait affirmé, les visages charbonneux, les corps marqués par l'âge et les conditions de vie, déformés, boursoufflés. Peu de place pour le décor et les plans larges. L'attention est tout entière pour les personnages et des portraits quasi photographiques, les yeux qui transpercent les planches et ces regards chargés, habités. La tendresse de l'auteur pour ces hommes et ces femmes est patente, à commencer par la figure bourrue, affectueuse, de Tenoir, fil conducteur d'un récit qui, à travers une famille, brosse l'histoire pluriséculaire de populations entières. Reste peut-être l'essentiel, cette façon d'être à soi et au monde, si ce n'est 

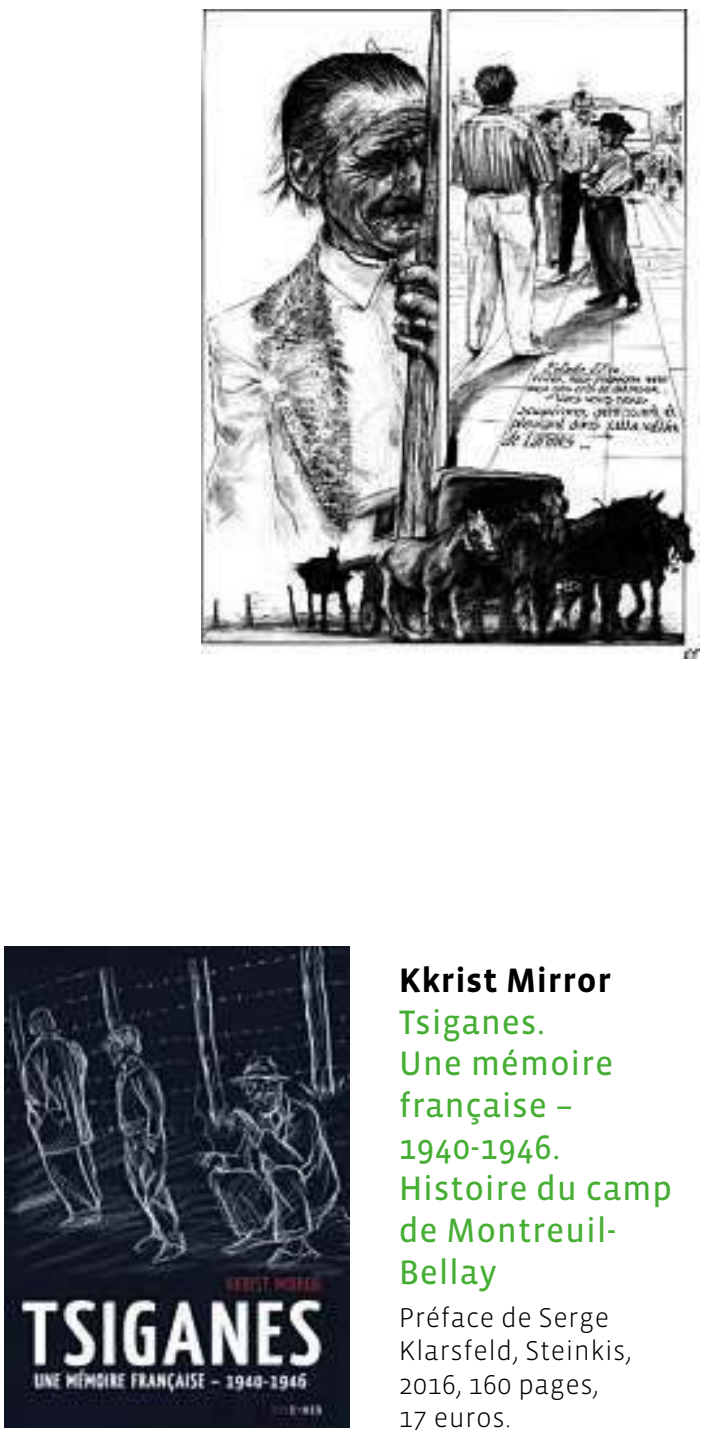

Kkrist Mirror

Tsiganes.

Une mémoire

française -

1940-1946.

Histoire du camp

de Montreuil-

Bellay

Préface de Serge Klarsfeld, Steinkis, 2016, 160 pages,

17 euros.

Encore une histoire de camp. La France n'en manque pas. Le livre s'ouvre, pleine page, sur une belle gueule de républicain espagnol. Manuel Sesma, réfugié, interné à Saint Cyprien, puis à Gurs, est envoyé à Montreuil du Bellay (Maine-etLoire) pour y construire, avec d'autres camarades d'infortune - Marocains, Algériens, Italiens, Portugais et Polonais-, unique, à tout le moins oubliée, menacée. Ici, Kkrist Mirror ouvre au lecteur, par les dessins et les mots, un chemin qui, de la narration, conduit à la reliance. l'humour, omniprésent, en est peut-être une clef. L'humour envers et contre tout (tous), contre les vicissitudes des temps et des hommes, contre le malheur et ses possibles résurgences, contre la mort ellemême. L'humour et la dérision ne célèbrent pas tant une joie de vivre que la vie elle-même, comme pour s'évader, tenir à distance le malheur. Rester libre. Cette valeur cardinale.

Mustapha Harzoune

ce qui deviendra en novembre 1941 le plus grand camp d'internement des Tsiganes en France. Sa fermeture attendra janvier 45 et, pour certains internés, la liberté ne viendra qu'en 1946, après un passage par les camps de Jargeau, de Pithiviers ou d'Angoulême. Ces Français, dont le seul tort était de préférer la liberté d'un ciel étoilé à la prison d'une maison, seront les derniers à être libérés. Ces Tsiganes voient arriver - et repartir - de nouveaux prisonniers, bien habillés ceux-là, les collabos, puis des Russes blancs ou des prostitués alsaciennes, objet de toutes les attentions et trafics... Mais eux, restent : "On sortira jamais! Comme les boches, ces gadjé veulent nous faire crever... ".

La justification-le crime et le criminel en exigent toujours une - pour enfermer fissa et manu militari plusieurs centaines 
de familles tsiganes et autres clochards et forains repose sur le danger que représenteraient ces « individus sans domicile fixe, nomades et forains", "ayant le type romani ». En gros, à partir d'avril 1940 et par décret, le manouche, voleur de poules et bouffeur de hérissons, pourrait bien être un espion!

La figure de l'abbé François Jollec éclaire ce récit. Aumônier autoproclamé du camp, il sera le ratchaï (curé) des romanos. Mais son action déplaît, Jollec est viré, renvoyé à ses ouailles. II se démène, avale à bicyclette des centaines de kilomètres pour convaincre les autorités civiles, religieuses, et même l'importun teuton, de revenir sur la décision. En vain. Chacun à sa façon fait comprendre à l'homme de foi et de fraternité qu'il fait bien trop de bruit pour des «bons à rien ». Comme l'écrit le préfacier, face au malheur et à l'injustice, impuissant, il ne reste au ratchaï qu'à "se saouler du vin du pays, de souffrance et de culpabilité".

L'album élargit la focale à cette France occupée, divisée entre pétainistes, collabos et résistants. Dans l'armée de l'ombre, on retrouve Jollec. Sur dénonciation, le réseau est démantelé, Jollec échappe à la vague d'arrestations. Dans un prêche dominical, il appelle l'assis- tance, en partie acquise à Pétain, à « faire corps avec ceux qui luttent et souffrent". À la Libération, en pleine vague d'épuration, l'abbé, toujours à secourir son prochain, saute sur une mine allemande. Il y perd un œil, un bras et une jambe ! À I'heure de la distribution, parfois injuste, des médailles, l'abbé s'éteint, anonyme. L'album se referme sur une note de I'historienne Marie-Christine Hubert, consacrée à l'histoire de l'internement des Tsiganes. Quant à Anne-Marie Kervern-Quéfféleant, elle raconte la vie de son grand-oncle, l'abbé François Jollec. Un texte admirable, élégant et tendre. Subtilement et fidèlement irrévérencieux.

Que sait-on de l'internement et de l'extermination des Tsiganes ? Pas grandchose sans doute. Le Tsigane préfère célébrer la vie plutôt que de s'adonner à l'instrumentalisation du malheur et de la mémoire. Moins par pudeur que pour ne pas attirer «le mauvais œil ». AnneMarie Kervern-Quéfféleant termine en citant Michelet, "si tous les hommes ne rentrent pas dans la cité,je reste dehors". Par les temps qui courent, les François Jollec risquent d'être nombreux. Dehors. I

M. H. 